\title{
Long-Term Quality of Life after Free Flap Upper Extremity Reconstruction for Traumatic Injuries
}

\author{
Sara van Bekkum, MD ${ }^{1}$ Tim de Jong, $\mathrm{MD}, \mathrm{PhD}^{1} \quad$ Michiel Zuidam, MD, $\mathrm{PhD}^{1}$ \\ Marc A. M. Mureau, MD, PhD ${ }^{10}$ \\ ${ }^{1}$ Department of Plastic and Reconstructive Surgery, Erasmus MC \\ Rotterdam, Rotterdam, The Netherlands \\ J Reconstr Microsurg 2020;36:213-222.

\begin{abstract}
Address for correspondence Marc A. M. Mureau, MD, PhD, Department of Plastic, Reconstructive and Hand Surgery, Erasmus MC, University Medical Center Rotterdam, P.O. Box 2040, NL-3000 CA, Rotterdam, The Netherlands (e-mail: m.mureau@erasmusmc.nl).
\end{abstract}

\begin{abstract}
Background Microsurgical reconstruction of upper extremity injuries is often challenging, and the resulting impact on the quality of life (QoL) may be significant. However, there is a lack of knowledge on long-term patient-reported QoL.

Methods In a retrospective long-term follow-up study, all consecutive patients with an upper extremity injury who had undergone a free flap reconstruction were identified and categorized into three groups based on the type of injury. Patientreported upper extremity function and QoL were assessed using three validated questionnaires: the 36-item Short Form Health Survey (SF-36), the Disabilities of the Arm, Shoulder, and Hand (DASH) questionnaire, and the Michigan Hand Outcomes Questionnaire (MHQ).

Results A total of 61 patients were identified, of whom $10 \%$ had undergone a free flap reconstruction for soft tissue loss only, $62 \%$ for an injury accompanied by a fracture, and $28 \%$ for a (sub) total amputation. Twenty-one (44\%) patients responded to the questionnaires, with a mean follow-up time of $9.7 \pm 6.2$ years. Patients, on average, reported poorer SF-36 "physical component score" and "role limitations due to physical health" scores compared with Dutch norms. Also, they reported poorer mean DASH scores compared with the general population, indicating worse upper extremity function. Mean $\mathrm{MQH}$ scores were lower for the injured side compared with the noninjured side. Pain correlated negatively with the total scores of DASH, MHQ, and

Keywords

- upper extremity

- free flap

- patient-reported outcomes

SF-36.

Conclusion Free flap upper extremity reconstruction is challenging. At 10 years of follow-up, the injury and its treatment continued to have a significant impact on the upper extremity function and daily QoL, with chronic pain being an important factor negatively affecting these outcomes.
\end{abstract}

Reconstruction of upper extremity injuries is often challenging because of the high functional properties of the hand, wrist, and arm. These injuries occur in a broad range of severity, frequently affecting patients' basic daily functioning. ${ }^{1,2}$ Consequently, they may have a significant impact on work and social life and are therefore expensive from a personal and

received

July 22, 2019

accepted after revision

October 10, 2019

published online

November 22, 2019 socioeconomic perspective, negatively affecting the general quality of life (QoL). ${ }^{1-4}$

Different treatment modalities are available for upper extremity injuries. However, complex forearm and hand injuries, specifically with soft tissue loss, often necessitate free flap reconstruction. ${ }^{5-7}$ Over the past decades, free flap
Copyright $\odot 2020$ by Thieme Medical Publishers, Inc., 333 Seventh Avenue, New York, NY 10001, USA. Tel: +1(212) 760-0888.
DOI https://doi.org/ 10.1055/s-0039-3400515. ISSN 0743-684X. 
reconstruction of these complex upper extremity defects have become a reliable standard-of-care approach. ${ }^{8-10}$

Most published studies on upper extremity reconstruction are retrospective with small study populations or mainly focused on surgical techniques and clinical outcomes without reporting the impact on QoL of these patients. ${ }^{11-13}$ Since upper extremity injuries may have a major effect on patients' functioning, patient-reported outcomes are crucial to evaluate treatment results. ${ }^{1,14}$ However, there is a lack of knowledge about the impact of severity of injury, treatment, and results, including postoperative complications, on longterm patient satisfaction and patient-reported outcomes after these microsurgical procedures. ${ }^{11}$

Therefore, the first aim of the present study was to assess long-term patient-reported upper extremity function and QoL after free flap reconstruction of severe upper extremity injuries. The second objective was to investigate possible relationships between patient and treatment variables and patient-reported outcomes.

\section{Methods}

\section{Study Design}

The present study was a retrospective cross-sectional longterm follow-up study of all consecutive patients who had received a free flap for an upper extremity injury between January 1993 and December 2014 at the Erasmus MC, Rotterdam, the Netherlands. The Medical Ethical Board of Erasmus MC approved the study (MEC-2016-345).

\section{Patient Selection}

Patients were included if they had undergone a free flap reconstruction following traumatic injury to the upper extremity and if surgical follow-up data of at least 30 days were available. Upper extremity free flap reconstructions for other indications were excluded.

All patients were treated following the local limb salvage protocol after traumatic upper extremity injury. Following this protocol, limb salvage is the treatment of choice. In case of traumatic amputation, feasibility for replantation is predominantly assessed based on neurovascular status. Hand and forearm amputations are always an indication for replantation. Replantation of digits occurs when two or more digits are amputated, with the exception of the thumb, which always qualifies replantation. Nerve grafts are used for nerve repair to bridge nerve gaps if necessary. Based on the length and thickness needed, the graft is harvested from the forearm (medial or lateral antebrachial cutaneous nerve) or lower leg (sural nerve). Depending on the level of bone injury, either primary fixation or arthrodesis is performed. Postoperative pain management is established on individual needs. No significant changes have been made to the protocol since its introduction.

Questionnaires were sent by mail if patients were 18 years or older, and at least 1-year follow-up was reached, or treatment had been finished. All questionnaires were sent at the same time in the spring of 2017, regardless of the time after trauma. Evaluation of patient-reported outcome measures
(PROMs) was performed at one moment in time, resulting in different follow-up times per patient. No further follow-up questionnaires were sent. When patients did not respond, a postal reminder was sent followed by a phone call. Written informed consent was obtained from all participating patients.

\section{Medical Data}

Patient-related variables were extracted from electronic medical records. Patient demographics, details of trauma, pre-, intra-, and postoperative treatment characteristics, and short- and long-term outcomes were collected. The following relevant comorbidities were scored: hypertension, diabetes mellitus, and vascular disease. The free flaps used were categorized into three groups: (1) skin grafted muscle, myocutaneous, or fasciocutaneous, (2) free bone flaps, and (3) a combination of multiple free flaps.

Patients were categorized into three groups based on the main type of traumatic injury: (1) patients with soft tissue injury only, (2) patients with injury accompanied by a bone fracture, and (3) patients with (sub) total amputation(s) at the level of the upper extremity.

\section{Questionnaires}

Patient-reported outcomes were assessed using three validated questionnaires: the 36-item Short Form Health Survey (SF-36), ${ }^{15,16}$ the Disabilities of the Arm, Shoulder, and Hand (DASH) questionnaire, ${ }^{17-19}$ and the Michigan Hand Outcomes Questionnaire (MHQ) ${ }^{20,21}$ The SF-36 gives insight into the general health status of patients based on 36 questions divided into eight domains, a physical component score (PCS), and a mental component score (MCS). The raw scores vary from 0 to 100 , with higher scores indicating a better functional well-being. ${ }^{15,16}$ The perception of disabilities and symptoms of the upper extremity were evaluated with two specific upper extremity questionnaires: the DASH and MHQ. The DASH is a 30 -item questionnaire including physical functioning items, symptom items, and social or role functioning items. Questions are scored on a 5-point Likert scale, and the raw score is transferred to scores ranging from 0 to 100 . A higher score indicates more disabilities. ${ }^{17-19}$ The MHQ gives insight into the hand function based on 63 questions organized in six domains, and also separately scores the left and right hands. Questions are scored on a 5-point Likert scale, and the raw scores are transferred to scores ranging from 0 to 100 , higher scores indicating a better hand function. ${ }^{20,21}$

\section{Statistical Analysis}

Patient-related variables were analyzed using descriptive statistics presented as means with standard deviations or as numbers with percentages. Univariate analyses using Fisher's exact tests, and nonparametric tests were performed to identify differences between the three groups for categorical and continuous variables, respectively. Spearman's correlation coefficients were used to study relationships between different outcomes. The SF-36 scores were compared with Dutch norms using independent sample Student's $t$-tests. ${ }^{16}$ The total DASH score was compared with the normative values reported 
by Hunsaker et al using independent sample Student's t-tests. ${ }^{22}$ No imputations were performed for missing data. Two-sided p-values of $<0.05$ were considered statistically significant. All statistical analyses were performed using the statistical software SPSS, Version 23 (IBM Corp., Armonk, NY).

\section{Results}

\section{Patient Characteristics}

Sixty-one consecutive patients were identified who had undergone a free flap reconstruction for a posttraumatic upper extremity injury between January 1993 and December 2014.

In group 1 , the majority were females (66.7\%), in contrast to groups 2 and 3 where the majority was male (89.5 and $88.2 \%$, respectively). Besides sex $(p=0.012)$, no statistically significant differences were found between the three groups with respect to patient demographics (-Table $\mathbf{1}$ ).

\section{Injury Characteristics}

The mechanisms of injury varied in group 1 ; in group 2 , in most cases, crush injuries were part of the mechanism of injury (57.9\%), and in group 3, it concerned crush (29.4\%), amputation (29.4\%), or blast injuries (41.2\%). Besides mechanism of injury $(p<0.001)$, no statistically significant differences were found between the three groups with respect to injury characteristics (- Table $\mathbf{1}$ ).

\section{Operation Characteristics}

In groups 1 and 3, in all cases, a soft tissue flap was used. In group 2, the majority of reconstructions (73.7\%) were with the use of a soft tissue free flap. Besides the flap type used $(p=0.031)$, no statistically significant differences were found between the three groups with respect to operation characteristics (- Table 2 ).

\section{Postoperative Course and Complications}

Twenty-five (40.9\%) patients developed a complication, of whom 11 (18\%) developed more than one complication. In total, 41 postoperative complications were identified, such as compromised vascularization of the flap (11.5\%), surgical site infection (11.5\%), skin necrosis (8.2\%), partial flap necrosis $(8.2 \%)$, and complete flap loss (9.8\%).

Nineteen (31.1\%) patients required reoperation for one or more complications (-Table 3 ). The majority (63.4\%) of complications occurred during the early postoperative period when patients were still admitted to the hospital.

Complete flap loss occurred in six (9.8\%) patients, of whom four had extensive crush injury due to machinery, one had extensive crush injury due to a severe traffic accident, and one had an extensive dog bite injury. In case of complete flap loss $(n=6)$, three patients received a salvage pedicled $(n=2)$ or free $(n=1)$ flap reconstruction and one patient received vacuumassisted closure therapy after which a functional pedicled reconstruction was performed approximately 2 years later. In two cases, a secondary amputation was inevitable due to vascularization problems and progressive necrosis of the flap.

In the other two patients, a secondary amputation was inevitable due to vascular compromise of the distal upper extremity due to the extensiveness of trauma without options for revascularization. A free flap was used as coverage of the stump.

No statistically significant differences were found between the three groups with respect to the postoperative course ( - Table 3 ).

\section{Patient-Reported Outcomes}

Forty-eight patients were eligible for PROMs, of whom 21 (44\%) responded to the questionnaires ( - Fig. 1 ), with a mean follow-up time of $9.7 \pm 6.2$ years. Patients who responded to the questionnaires had a significantly higher mean age compared with those who did not respond $(p=0.023)$. Besides age, no other significant differences in patient, trauma, and postoperative characteristics were found between responders and nonresponders (-Table 4 ).

No statistically significant differences were found between the three groups in terms of mean SF-36 MCS $(p=0.651)$, SF-36 PCS $(p=0.776)$, DASH score $(p=0.189)$, and total MHQ score $(p=0.413)$ (-Table 5)

The severity of injury, timing of operation, level of injury, and the occurrence of postoperative complications were associated with neither the total MHQ scores of the injured hand ( $p=0.385, p=0.608, p=0.693$, and $p=0.104$, respectively) nor the DASH scores $(p=0.185, p=0.802, p=0.484$, and $p=0.157$, respectively).

Patients reported significantly poorer MHQ scores of their injured side compared with their noninjured side, with a mean total hand score of $66.0 \pm 23.0$ versus $85.8 \pm 14.7$, respectively ( $p=0.005$ ). Still, $57 \%$ of the patients were satisfied with the overall hand function of the injured side.

The SF-36 "bodily pain" score showed a significant correlation with the DASH score $(\rho=-0.48 ; p=0.032)$ and the total MHQ score $(\rho=0.49 ; p=0.037)$. The raw pain score of the MHQ significantly correlated with the DASH score $(\rho=0.56$; $p=0.017)$ but not with PCS $(\rho=-0.35 ; p=0.139)$ and MCS $(\rho=-0.23 ; p=0.339)$.

Patients from the current study, on average, reported poorer DASH scores $(24.2 \pm 23.5)$ compared with the general population $(p=0.015)$. Furthermore, patients reported much poorer SF-36 PCS and "role limitations due to physical health" scores compared with Dutch norms $(p=0.004$ and $p=0.016$, respectively). For the other SF-36 domains and MCS, no differences were found (-Table $\mathbf{6}$ ).

\section{Discussion}

Severe traumatic upper extremity injuries pose a challenge in preserving the upper limb and often necessitate microvascular reconstruction. These reconstructions are necessary not only for soft tissue repair, but also to maintain an adequate upper extremity function. Nevertheless, knowledge on the outcomes after microsurgical reconstruction of these extensive upper extremity injuries, including long-term patient-reported outcomes, is missing. The current study showed that after more than 10 years follow-up, patients reported poorer QoL and functional outcomes compared with the general population. However, these results were not related to operation 
Table 1 Patient characteristics of 61 patients with a free flap reconstruction for a severe posttraumatic upper extremity injury

\begin{tabular}{|c|c|c|c|c|}
\hline & $\begin{array}{l}\text { Soft tissue injury } \\
\text { only }(n=6)\end{array}$ & $\begin{array}{l}\text { (Open) fracture } \\
(n=38)\end{array}$ & $\begin{array}{l}\text { (Sub) total } \\
\text { amputation }(n=17)\end{array}$ & $p$-Value \\
\hline Mean age $\pm S D, y$ & $40.0 \pm 5.9$ & $36.6 \pm 15.2$ & $38.2 \pm 15.8$ & 0.854 \\
\hline Mean $\mathrm{BMI} \pm \mathrm{SD}, \mathrm{kg} / \mathrm{m}^{2}$ & $22.7 \pm 2.9$ & $24.6 \pm 4.0$ & $23.9 \pm 6.6$ & 0.719 \\
\hline \multicolumn{5}{|l|}{ Sex } \\
\hline Male & $2(33.3 \%)$ & 34 (89.5\%) & $15(88.2 \%)$ & \multirow[t]{2}{*}{0.012} \\
\hline Female & $4(66.7 \%)$ & $4(10.5 \%)$ & $2(11.8 \%)$ & \\
\hline \multicolumn{5}{|l|}{ Smoker } \\
\hline No & $3(50.0 \%)$ & $22(61.1 \%)$ & $11(73.3 \%)$ & \multirow[t]{2}{*}{0.550} \\
\hline Yes & $3(50.0 \%)$ & $14(38.9 \%)$ & $4(26.7 \%)$ & \\
\hline \multicolumn{5}{|l|}{ Comorbidities } \\
\hline No & $6(100 \%)$ & 34 (89.5\%) & $16(94.1 \%)$ & \multirow[t]{2}{*}{0.493} \\
\hline Yes & & $4(10.5 \%)$ & $1(5.9 \%)$ & \\
\hline \multicolumn{5}{|l|}{ Injured side } \\
\hline Left & $3(50.0 \%)$ & $20(52.6 \%)$ & $12(70.6 \%)$ & \multirow[t]{2}{*}{0.418} \\
\hline Right & $3(50.0 \%)$ & $18(47.4 \%)$ & $5(29.4 \%)$ & \\
\hline \multicolumn{5}{|l|}{ Dominant side injured } \\
\hline No & $2(33.3 \%)$ & $18(47.4 \%)$ & $11(73.3 \%)$ & \multirow[t]{3}{*}{0.393} \\
\hline Yes & $2(33.3 \%)$ & 15 (39.5\%) & $3(17.6 \%)$ & \\
\hline Unknown & $2(33.3 \%)$ & $5(13.2 \%)$ & $3(17.6 \%)$ & \\
\hline \multicolumn{5}{|l|}{ Location of defect } \\
\hline Upper arm/elbow & $1(16.7 \%)$ & $3(7.9 \%)$ & $1(5.9 \%)$ & \multirow[t]{3}{*}{0.633} \\
\hline Forearm & $2(33.3 \%)$ & $13(34.2 \%)$ & $3(17.6 \%)$ & \\
\hline Wrist/hand & $3(50.0 \%)$ & $22(57.9 \%)$ & $13(76.5 \%)$ & \\
\hline \multicolumn{5}{|l|}{ Extension trauma } \\
\hline $\begin{array}{l}\text { Trauma limited to the } \\
\text { upper extremity }\end{array}$ & $6(100 \%)$ & 34 (89.5\%) & $15(88.2 \%)$ & \multirow[t]{2}{*}{0.514} \\
\hline Polytrauma & & $4(10.5 \%)$ & $2(11.8 \%)$ & \\
\hline \multicolumn{5}{|l|}{ Mechanism of injury } \\
\hline Crush & $1(16.7 \%)$ & $16(42.1 \%)$ & $5(29.4 \%)$ & \multirow[t]{10}{*}{$<0.001$} \\
\hline Avulsion & $1(16.7 \%)$ & $1(2.6 \%)$ & & \\
\hline Degloving & & $3(7.9 \%)$ & & \\
\hline Crush and degloving & $1(16.7 \%)$ & $4(10.5 \%)$ & & \\
\hline Crush and avulsion & & $2(5.3 \%)$ & & \\
\hline Amputation & & $1(2.6 \%)$ & $5(29.4 \%)$ & \\
\hline Firework/blast injury & & $2(5.3 \%)$ & $7(41.2 \%)$ & \\
\hline Sharp/bite injury & $2(33.3 \%)$ & $1(7.9 \%)$ & & \\
\hline Burn injury & $1(16.7 \%)$ & & & \\
\hline Bone fracture & & $6(15.8 \%)$ & & \\
\hline
\end{tabular}

Abbreviation: SD, standard deviation.

Note: The significant value is shown in bold.

indication, complications, severity of injury, level of injury, and timing of operation. As expected, chronic pain correlated with poorer functional outcomes and the injured side obviously was associated with poorer results compared with the noninjured side. Still, a majority of the patients were satisfied with the obtained results.
Severe upper extremity injuries typically need complex and extensive surgery, leading to long operative times, prolonged hospitalization, and an increased risk of complications. In the current study, $11 \%$ of the patients developed a postoperative surgical site infection, all at the recipient site. In the available literature, postoperative infections after free 
Table 2 Operation characteristics of 61 patients with a free flap reconstruction for a severe posttraumatic upper extremity injury

\begin{tabular}{|c|c|c|c|c|}
\hline & $\begin{array}{l}\text { Soft tissue injury } \\
\text { only }(n=6)\end{array}$ & $\begin{array}{l}\text { (Open) fracture } \\
(n=38)\end{array}$ & $\begin{array}{l}\text { (Sub) total } \\
\text { amputation }(n=17)\end{array}$ & $p$-Value \\
\hline Operation time, hours:minutes & $9: 27 \pm 2: 59$ & $10: 58 \pm 3: 57$ & $10: 33 \pm 2: 52$ & 0.600 \\
\hline Ischemia time, hours:minutes & $1: 22 \pm 0: 45$ & $1: 31 \pm 0: 44$ & $1: 31 \pm 0: 58$ & 0.917 \\
\hline \multicolumn{5}{|l|}{ Indication for free flap } \\
\hline Soft tissue defect & $5(83.3 \%)$ & $26(68.4 \%)$ & $15(88.2 \%)$ & \multirow[t]{2}{*}{0.231} \\
\hline Functional reconstruction & $1(16.7 \%)$ & $12(31.6 \%)$ & $2(11.8 \%)$ & \\
\hline \multicolumn{5}{|l|}{ Specification functional reconstruction } \\
\hline Nerve and tendon reconstruction & & $3(7.9 \%)$ & $1(5.9 \%)$ & \multirow[t]{5}{*}{0.404} \\
\hline First web space reconstruction & & $1(2.6 \%)$ & & \\
\hline $\begin{array}{l}\text { Posttraumatic arthroses/nonunion } \\
\text { with pain/functional limitations }\end{array}$ & $1(16.7 \%)$ & $7(18.4 \%)$ & & \\
\hline Stabilization and nerve reconstruction & & $1(2.6 \%)$ & & \\
\hline Tendon reconstruction + soft tissue defect & & & $1(5.9 \%)$ & \\
\hline \multicolumn{5}{|l|}{ Timing of operation } \\
\hline$<6$ wk & $5(83.3 \%)$ & $24(63.2 \%)$ & $13(76.5 \%)$ & \multirow[t]{2}{*}{0.362} \\
\hline$>6 w k$ & $1(16.7 \%)$ & $13(34.2 \%)$ & $3(17.6 \%)$ & \\
\hline \multicolumn{5}{|l|}{ Flap type } \\
\hline Soft tissue flap & $6(100 \%)$ & $28(73.7 \%)$ & $17(100 \%)$ & \multirow[t]{3}{*}{0.031} \\
\hline Bone flap & & $9(23.7 \%)$ & & \\
\hline Combination of multiple flaps & & $1(2.6 \%)$ & & \\
\hline \multicolumn{5}{|l|}{ Type of arterial anastomosis } \\
\hline End-to-side & $1(16.7 \%)$ & $16(42.1 \%)$ & $9(52.9 \%)$ & \multirow[t]{3}{*}{0.265} \\
\hline End-to-end & $4(66.7 \%)$ & $13(34.2 \%)$ & $6(35.3 \%)$ & \\
\hline Missing & $1(16.7 \%)$ & $9(23.7 \%)$ & $2(11.8 \%)$ & \\
\hline \multicolumn{5}{|l|}{ Type of venous anastomosis } \\
\hline End-to-side & & $2(5.3 \%)$ & $2(11.8 \%)$ & \multirow[t]{3}{*}{0.496} \\
\hline End-to-end & $5(83.3 \%)$ & $28(73.7 \%)$ & $13(76.5 \%)$ & \\
\hline Missing & $1(16.7 \%)$ & $8(21.1 \%)$ & $2(11.8 \%)$ & \\
\hline
\end{tabular}

Note: The significant value is shown in bold.

flap reconstruction of upper extremity injuries have been reported in 7 to $28 \%$ patients. $5,10,12,13,23$

In line with previous studies, the complete free flap survival rate in the present study was 90\%. ${ }^{10,24,25}$ The majority of the patients with total flap loss had severe and extensive crush injuries. In case of vascular flap compromise, the flap salvage rate after reexploration was $54 \%$, which is in line with our previous study on risk factors for free flap failure in 1,530 free flaps. ${ }^{26}$

Following microsurgical reconstruction of severe upper extremity injuries, the affected limb often keeps suffering from functional impairment, ${ }^{8,10,27}$ which has been previously found by other studies using PROMs. ${ }^{28-32}$ Although the reported DASH scores (8-71) and MHQ scores (47-77) ranged considerably, all authors emphasized limb preservation as the treatment of choice. ${ }^{28-32}$ Our results corroborate these findings and support the statement that extensive reconstruction is the preferred and often the only treatment possible for limb and/or function preservation. Although the mean DASH scores (24) and the mean total MHQ scores (66) from the present study imply significant functional impairment, over half of the patients reported to be satisfied. This satisfaction may indicate the effect of coping after such severe trauma. ${ }^{33-36}$ The patient-reported upper extremity function and QoL, which in the current study were poorer compared with the general population, indicate the longterm impact on daily functioning of severe upper extremity injuries and stresses the need for good patient counseling and patient expectation management. ${ }^{37}$

Pain appeared to be an important factor that negatively affected long-term functional outcomes and QoL. The results of the present study showed a negative correlation between chronic pain and total scores of the DASH, MHQ and SF-36. This is in accordance with previous studies, which also reported chronic pain as a long-term disabling symptom after extremity injuries. $4,38,39$ Therefore, early adequate pain management is advocated to improve long-term functional outcomes and QoL. ${ }^{4,39}$ Besides pain, no other significant predictive factors 
Table 3 Postoperative admission time and complications of 61 patients with a free flap reconstruction for a severe posttraumatic upper extremity injury

\begin{tabular}{|c|c|c|c|c|}
\hline & $\begin{array}{l}\text { Soft tissue injury } \\
\text { only }(n=6)\end{array}$ & $\begin{array}{l}\text { (Open) fracture } \\
(n=38)\end{array}$ & $\begin{array}{l}\text { (Sub) total amputation } \\
(n=17)\end{array}$ & $p$-Value \\
\hline Admission, $d$ & $28.7 \pm 20.5$ & $19.7 \pm 14.3$ & $19.8 \pm 10.8$ & 0.476 \\
\hline \multicolumn{5}{|l|}{ Postoperative complication } \\
\hline No & $3(50.0 \%)$ & $24(63.2 \%)$ & $9(52.9 \%)$ & \multirow[t]{2}{*}{0.695} \\
\hline Yes & $3(50.0 \%$ & $14(36.8 \%)$ & $8(47.1 \%)$ & \\
\hline \multicolumn{5}{|c|}{ Reoperation due to complication } \\
\hline No & $1(16.7 \%)$ & $2(5.3 \%)$ & $3(17.6 \%)$ & \multirow[t]{2}{*}{0.435} \\
\hline Yes & $2(33.3 \%)$ & $12(31.6 \%)$ & $5(29.4 \%)$ & \\
\hline \multicolumn{5}{|c|}{ Complications that required reoperation } \\
\hline Vascular compromise flap & $1(16.7 \%)$ & $6(15.8 \%)$ & $4(23.5 \%)$ & \\
\hline Partial flap necrosis & $1(16.7 \%)$ & $2(5.3 \%)$ & $1(5.9 \%)$ & \\
\hline Total flap loss & $1(16.7 \%)$ & $5(13.2 \%)$ & & \\
\hline Infection & & $1(2.6 \%)$ & & \\
\hline Other & & $3(7.9 \%)$ & & \\
\hline \multicolumn{5}{|l|}{ Total flap loss } \\
\hline No & $5(83.3 \%)$ & $33(86.8 \%)$ & $17(100 \%)$ & \multirow[t]{2}{*}{0.121} \\
\hline Yes & $1(16.7 \%)$ & $5(13.2 \%)$ & & \\
\hline \multicolumn{5}{|l|}{ Secondary amputation } \\
\hline No & $6(100 \%)$ & $35(92.1 \%)$ & $16(94.1 \%)$ & \multirow[t]{2}{*}{0.617} \\
\hline Yes & & $3(7.9 \%)$ & $1(5.9 \%)$ & \\
\hline
\end{tabular}

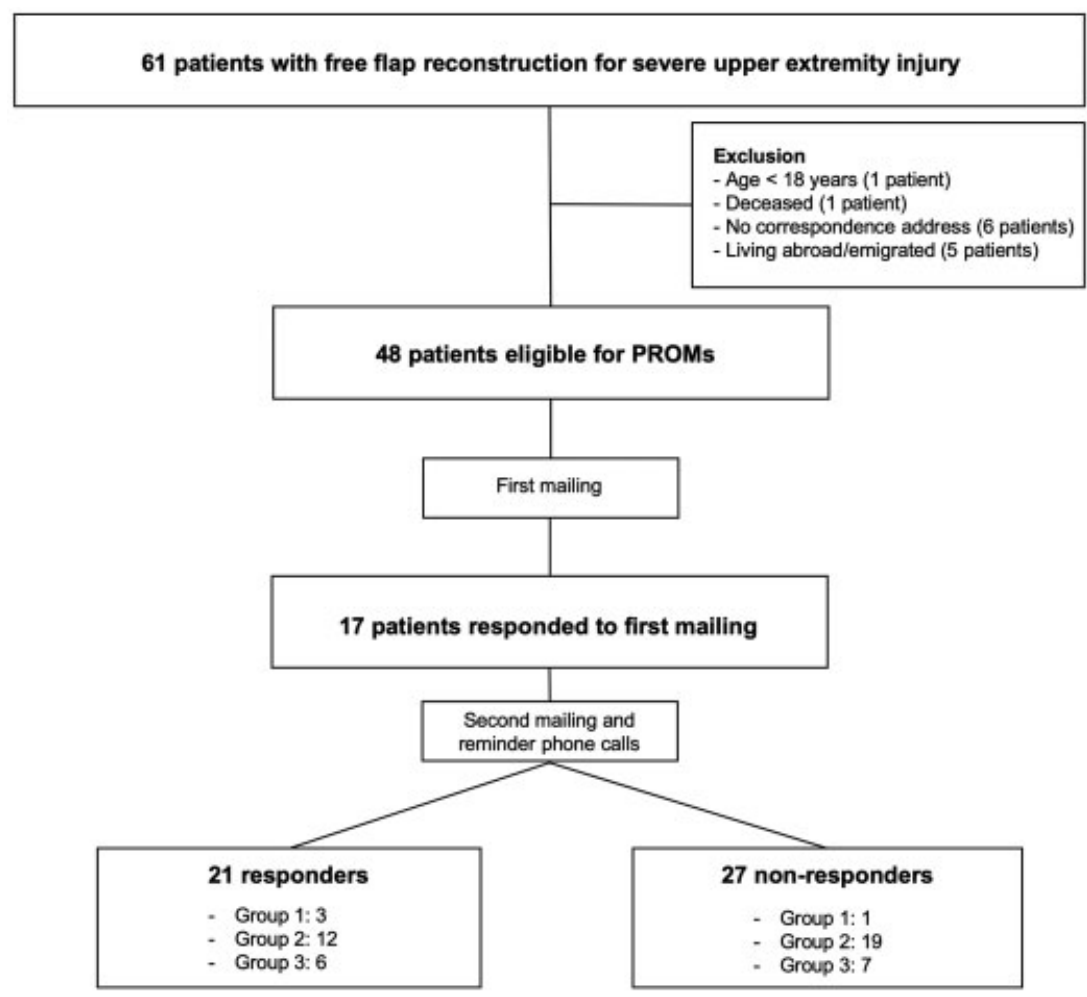

Fig. 1 Flowchart of the responders to the patient-reported outcome measures. Group 1: patients with soft tissue injury only. Group 2: patients with injury accompanied by a bone fracture. Group 3: patients with (sub) total amputation(s) at the level of the upper extremity. 
Table 4 Characteristics of 27 nonresponders compared with 21 responders with a free flap reconstruction for a severe posttraumatic upper extremity injury

\begin{tabular}{|c|c|c|c|}
\hline & Nonresponders $(n=27)$ & Responders $(n=21)$ & p-Value \\
\hline Mean age $\pm S D, y$ & $32.4 \pm 13.6$ & $41.7 \pm 13.3$ & 0.023 \\
\hline Mean follow-up time $\pm S D, y$ & $10.1 \pm 6.2$ & $9.7 \pm 6.2$ & 0.851 \\
\hline \multicolumn{4}{|l|}{ Sex } \\
\hline Male & $25(92.6 \%)$ & $15(71.4 \%)$ & \multirow[t]{2}{*}{0.115} \\
\hline Female & $2(7.4 \%)$ & $6(28.6 \%)$ & \\
\hline \multicolumn{4}{|l|}{ Smoker } \\
\hline No & $13(52.0 \%)$ & $13(65.0 \%)$ & \multirow[t]{2}{*}{0.380} \\
\hline Yes & $12(48.0 \%)$ & $7(35.0 \%)$ & \\
\hline \multicolumn{4}{|l|}{ Comorbidities } \\
\hline No & $25(92.6 \%)$ & $20(95.2 \%)$ & \multirow[t]{2}{*}{1.000} \\
\hline Yes & $2(7.4 \%)$ & $1(4.8 \%)$ & \\
\hline \multicolumn{4}{|l|}{ Type of injury } \\
\hline Soft tissue injury only & $1(3.7 \%)$ & $3(14.3 \%)$ & \multirow[t]{3}{*}{0.374} \\
\hline Fracture & $19(70.4 \%)$ & $12(57.1 \%)$ & \\
\hline (sub) total amputation & $7(25.9 \%)$ & $6(28.6 \%)$ & \\
\hline \multicolumn{4}{|l|}{ Dominant side injured } \\
\hline No & $14(51.9 \%)$ & $11(52.4 \%)$ & \multirow[t]{3}{*}{0.626} \\
\hline Yes & $8(29.6 \%)$ & $8(38.1 \%)$ & \\
\hline Unknown & $5(18.5 \%)$ & $2(9.5 \%)$ & \\
\hline \multicolumn{4}{|l|}{ Extension trauma } \\
\hline Trauma limited to the upper extremity & $25(92.6 \%)$ & $18(85.7 \%)$ & \multirow[t]{2}{*}{0.641} \\
\hline Polytrauma & $2(7.4 \%)$ & $3(14.3 \%)$ & \\
\hline \multicolumn{4}{|l|}{ Timing of operation } \\
\hline$<6$ wk & $17(65.4 \%)$ & $14(70.0 \%)$ & \multirow[t]{2}{*}{0.741} \\
\hline$>6 w k$ & $9(34.6 \%)$ & $6(30.0 \%)$ & \\
\hline \multicolumn{4}{|l|}{ Complicated course } \\
\hline No & $16(59.3 \%)$ & $13(61.9 \%)$ & \multirow[t]{2}{*}{0.853} \\
\hline Yes & $11(40.7 \%)$ & $8(38.1 \%)$ & \\
\hline
\end{tabular}

Abbreviation: SD, standard deviation.

Note: The significant value is shown in bold.

Table 5 Long-term patient-reported outcomes of 21 patients with a free flap reconstruction for a severe posttraumatic upper extremity injury

\begin{tabular}{|c|c|c|c|c|}
\hline & $\begin{array}{l}\text { Soft tissue injury } \\
\text { only }(n=3)\end{array}$ & $\begin{array}{l}\text { (Open) fracture } \\
(n=12)\end{array}$ & $\begin{array}{l}\text { (Sub) total } \\
\text { amputation }(n=6)\end{array}$ & $p$-Value \\
\hline SF-36 PCS, mean \pm SD & $43.7 \pm 9.9$ & $46.1 \pm 8.3$ & $42.6 \pm 12.3$ & 0.776 \\
\hline SF-36 MCS, mean \pm SD & $46.8 \pm 14.0$ & $53.6 \pm 10.7$ & $51.2 \pm 10.7$ & 0.651 \\
\hline DASH total score, mean \pm SD & $30.3 \pm 30.6$ & $17.0 \pm 21.8$ & $34.2 \pm 22.9$ & 0.189 \\
\hline $\begin{array}{l}\text { MHQ total score of the } \\
\text { injured side, mean } \pm \text { SD }\end{array}$ & $76.0 \pm 5.0$ & $68.7 \pm 26.3$ & $55.9 \pm 17.4$ & 0.413 \\
\hline
\end{tabular}

Abbreviations: DASH, Disabilities of the Arm, Shoulder, and Hand questionnaire; MHQ, Michigan Hand outcomes Questionnaire; MCS, mental component score; PCS, physical component score; SD, standard deviation; SF-36, 36-item Short-Form Health Survey.

for a poor functional outcome could be identified, possibly due to the low power of the current study.

The response rate to the questionnaires was rather low despite reminder phone calls and a second mailing. The low response rate can be explained by factors associated with nonresponse, such as younger age, and male sex, since the majority of the current study population were young males. ${ }^{40,41}$ Other studies reported poorer outcomes of nonresponders than 
Table 6 SF-36 and DASH patient-reported outcomes of 21 patients with a free flap reconstruction for a severe posttraumatic upper extremity injury compared with the general population

\begin{tabular}{|c|c|c|c|}
\hline & Study population & General population & $p$-Value \\
\hline \multicolumn{4}{|l|}{ SF-36: physical functioning } \\
\hline$n$ & 21 & 1,718 & \multirow[t]{2}{*}{0.279} \\
\hline Mean \pm standard deviation & $79.2 \pm 16.3$ & $83.2 \pm 22.6$ & \\
\hline \multicolumn{4}{|c|}{ SF-36: role limitations due to physical health } \\
\hline$n$ & 21 & 1,693 & \multirow[t]{2}{*}{0.004} \\
\hline Mean \pm standard deviation & $53.6 \pm 43.5$ & $76.6 \pm 36.1$ & \\
\hline \multicolumn{4}{|l|}{ SF-36: bodily pain } \\
\hline$N$ & 21 & 1,729 & \multirow[t]{2}{*}{0.059} \\
\hline Mean \pm standard deviation & $65.3 \pm 26.5$ & $75.0 \pm 23.3$ & \\
\hline \multicolumn{4}{|c|}{ SF-36: role limitation due to emotional problems } \\
\hline$N$ & 21 & 1,686 & \multirow[t]{2}{*}{0.835} \\
\hline Mean \pm standard deviation & $81.0 \pm 37.4$ & $82.5 \pm 32.8$ & \\
\hline \multicolumn{4}{|l|}{ SF-36: general health perception } \\
\hline$N$ & 21 & 1,705 & \multirow[t]{2}{*}{0.859} \\
\hline Mean \pm standard deviation & $70.1 \pm 18.2$ & $70.9 \pm 20.6$ & \\
\hline \multicolumn{4}{|l|}{ SF-36: vitality } \\
\hline$N$ & 21 & 1,715 & \multirow[t]{2}{*}{0.654} \\
\hline Mean \pm standard deviation & $66.7 \pm 19.2$ & $68.6 \pm 19.3$ & \\
\hline \multicolumn{4}{|l|}{ SF-36: social functioning } \\
\hline$N$ & 21 & 1,729 & \multirow[t]{2}{*}{0.308} \\
\hline Mean \pm standard deviation & $79.2 \pm 25.4$ & $84.2 \pm 22.3$ & \\
\hline \multicolumn{4}{|l|}{ SF-36: mental health } \\
\hline$N$ & 21 & 1,714 & \multirow[t]{2}{*}{0.448} \\
\hline Mean \pm standard deviation & $74.0 \pm 18.1$ & $76.9 \pm 17.4$ & \\
\hline \multicolumn{4}{|l|}{ SF-36: PCS } \\
\hline$N$ & 21 & 1,657 & \multirow[t]{2}{*}{0.016} \\
\hline Mean \pm standard deviation & $44.7 \pm 9.4$ & $50.0 \pm 10.0$ & \\
\hline \multicolumn{4}{|l|}{ SF-36: MCS } \\
\hline$N$ & 21 & 1,657 & \multirow[t]{2}{*}{0.363} \\
\hline Mean \pm standard deviation & $52.0 \pm 10.8$ & $50.0 \pm 10.0$ & \\
\hline \multicolumn{4}{|l|}{ DASH: total score } \\
\hline$N$ & 20 & 1,706 & \multirow[t]{2}{*}{0.015} \\
\hline Mean \pm standard deviation & $24.2 \pm 23.5$ & $10.1 \pm 14.7$ & \\
\hline
\end{tabular}

Abbreviations: DASH, Disabilities of the Arm, Shoulder, and Hand questionnaire; MCS, mental component score; PCS, physical component score; SF36, 36-item Short-Form Health Survey.

Note: The significant value is shown in bold.

responders. ${ }^{42,43}$ However, besides older age, no differences in patient, clinical, and operation characteristics were found between responders and nonresponders. Therefore, we presume that responders were representative of the entire patient cohort.

This study was limited by its retrospective design, which resulted in missing data. Although no statistically significant differences were found, these missing data in combination with the rather low response rate could have resulted in some bias. Another limitation was the large variation in patients and their injury and operation characteristics. Based on the type of injury, patients were categorized into three groups to be able to make meaningful comparisons. However, there still remained large intragroup variations in the mechanisms of injury, severity of injury, extensiveness of injury, and operation characteristics, probably causing a large variation in clinical and patient-reported outcomes. However, the power of the current study was too small to correct for these variations and perform multivariate analysis. Therefore, these outcomes should be interpreted with care. 


\section{Conclusion}

Free flap reconstruction of severe upper extremity injuries is an effective method to manage extensive posttraumatic defects of the upper extremity. At 10 years of follow-up, the injury and its treatment continued to have a clear impact on daily QoL, with chronic pain being an important factor negatively affecting functional outcomes and QoL.

\section{Funding \\ None. \\ Conflict of Interest \\ None declared.}

\section{References}

1 Hegge T, Neumeister MW. Mutilated hand injuries. Clin Plast Surg 2011;38(04):543-550

2 Rosberg HE, Carlsson KS, Dahlin LB. Prospective study of patients with injuries to the hand and forearm: costs, function, and general health. Scand J Plast Reconstr Surg Hand Surg 2005;39(06): 360-369

3 Matsuzaki H, Narisawa H, Miwa H, Toishi S. Predicting functional recovery and return to work after mutilating hand injuries: usefulness of Campbell's Hand Injury Severity Score. J Hand Surg Am 2009;34(05):880-885

4 Meyer TM. Psychological aspects of mutilating hand injuries. Hand Clin 2003;19(01):41-49

5 Harrison BL, Lakhiani C, Lee MR, Saint-Cyr M. Timing of traumatic upper extremity free flap reconstruction: a systematic review and progress report. Plast Reconstr Surg 2013;132(03):591-596

6 Stevanovic M, Sharpe F. Functional free muscle transfer for upper extremity reconstruction. Plast Reconstr Surg 2014;134(02): 257e-274e

7 Bumbasirevic M, Stevanovic M, Lesic A, Atkinson HD. Current management of the mangled upper extremity. Int Orthop 2012; 36(11):2189-2195

8 Panattoni JB, Ahmed MM, Busel GA. An ABC technical algorithm to treat the mangled upper extremity: systematic surgical approach. J Hand Surg Am 2017;42(11):934.e1-934.e10

9 Dolan RT, Butler JS, Murphy SM, Cronin KJ. Health-related quality of life, surgical and aesthetic outcomes following microvascular free flap reconstructions: an 8-year institutional review. Ann $\mathrm{R}$ Coll Surg Engl 2012;94(01):43-51

10 Prasarn ML, Helfet DL, Kloen P. Management of the mangled extremity. Strateg Trauma Limb Reconstr 2012;7(02):57-66

11 Cano SJ, Browne JP, Lamping DL. Patient-based measures of outcome in plastic surgery: current approaches and future directions. Br J Plast Surg 2004;57(01):1-11

12 Gupta A, Lakhiani C, Lim BH, et al. Free tissue transfer to the traumatized upper extremity: risk factors for postoperative complications in 282 cases. J Plast Reconstr Aesthet Surg 2015;68(09): $1184-1190$

13 Derderian CA, Olivier WA, Baux G, Levine J, Gurtner GC. Microvascular free-tissue transfer for traumatic defects of the upper extremity: a 25-year experience. J Reconstr Microsurg 2003;19 (07):455-462

14 Wormald JCR, Rodrigues JN. Outcome measurement in plastic surgery. J Plast Reconstr Aesthet Surg 2018;71(03):283-289

15 Ware JE Jr, Sherbourne CD. The MOS 36-item short-form health survey (SF-36). I. Conceptual framework and item selection. Med Care 1992;30(06):473-483

16 Aaronson NK, Muller M, Cohen PD, et al. Translation, validation, and norming of the Dutch language version of the SF-36 Health
Survey in community and chronic disease populations. J Clin Epidemiol 1998;51(11):1055-1068

17 Hudak PL, Amadio PC, Bombardier C; The Upper Extremity Collaborative Group (UECG). Development of an upper extremity outcome measure: the DASH (Disabilities of the Arm, Shoulder and Hand) [corrected]. Am J Ind Med 1996;29(06):602-608

18 Beaton DE, Katz JN, Fossel AH, Wright JG, Tarasuk V, Bombardier C. Measuring the whole or the parts? Validity, reliability, and responsiveness of the Disabilities of the Arm, Shoulder and Hand outcome measure in different regions of the upper extremity. J Hand Ther 2001;14(02):128-146

19 Veehof MM, Sleegers EJ, van Veldhoven NH, Schuurman AH, van Meeteren NL. Psychometric qualities of the Dutch language version of the Disabilities of the Arm, Shoulder, and Hand questionnaire (DASH-DLV). J Hand Ther 2002;15(04):347-354

20 Chung KC, Pillsbury MS, Walters MR, Hayward RA. Reliability and validity testing of the Michigan Hand Outcomes Questionnaire. J Hand Surg Am 1998;23(04):575-587

21 Chung KC, Hamill JB, Walters MR, Hayward RA. The Michigan Hand Outcomes Questionnaire (MHQ): assessment of responsiveness to clinical change. Ann Plast Surg 1999;42(06):619-622

22 Hunsaker FG, Cioffi DA, Amadio PC, Wright JG, Caughlin B. The American academy of orthopaedic surgeons outcomes instruments: normative values from the general population. J Bone Joint Surg Am 2002;84(02):208-215

23 Hsu CC, Lin YT, Lin CH, Lin CH, Wei FC. Immediate emergency free anterolateral thigh flap transfer for the mutilated upper extremity. Plast Reconstr Surg 2009;123(06):1739-1747

24 Sauerbier M, Ofer N, Germann G, Baumeister S. Microvascular reconstruction in burn and electrical burn injuries of the severely traumatized upper extremity. Plast Reconstr Surg 2007;119(02): 605-615

25 Godina M. Early microsurgical reconstruction of complex trauma of the extremities. Plast Reconstr Surg 1986;78(03):285-292

26 Las DE, de Jong T, Zuidam JM, Verweij NM, Hovius SER, Mureau MAM. Identification of independent risk factors for flap failure: a retrospective analysis of 1530 free flaps for breast, head and neck and extremity reconstruction. J Plast Reconstr Aesthet Surg 2016; 69(07):894-906

27 Malahias M, Jordan DJ, Hindocha S, Khan W, Juma A. The development and future of reconstructive and microvascular surgery of the hand. Open Orthop J 2014;8(01):415-422

28 Chung KC, Yoon AP, Malay S, Shauver MJ, Wang L, Kaur S; FRANCHISE Group. Patient-reported and functional outcomes after revision amputation and replantation of digit amputations: the FRANCHISE multicenter international retrospective cohort study. JAMA Surg 2019;154(07):637-646

29 Sabapathy SR, Satbhai NG. Microsurgery in the urgent and emergent management of the hand. Curr Rev Musculoskelet Med 2014;7(01):40-46

30 Pet MA, Morrison SD, Mack JS, et al. Comparison of patientreported outcomes after traumatic upper extremity amputation: replantation versus prosthetic rehabilitation. Injury 2016;47(12): 2783-2788

31 Stanger K, Horch RE, Dragu A. Severe mutilating injuries with complex macroamputations of the upper extremity - is it worth the effort? World J Emerg Surg 2015;10:30

32 Kremer T, Bickert B, Germann G, Heitmann C, Sauerbier M. Outcome assessment after reconstruction of complex defects of the forearm and hand with osteocutaneous free flaps. Plast Reconstr Surg 2006;118(02):443-454, discussion 455-456

33 George JM, Scott DS, Turner SP, Gregg JM. The effects of psychological factors and physical trauma on recovery from oral surgery. J Behav Med 1980;3(03):291-310

34 Jayakumar P, Overbeek CL, Lamb S, et al. What factors are associated with disability after upper extremity injuries? A systematic review. Clin Orthop Relat Res 2018;476(11): $2190-2215$ 
35 Giladi AM, Ranganathan K, Chung KC. Measuring functional and patient-reported outcomes after treatment of mutilating hand injuries: a global health approach. Hand Clin 2016;32(04): 465-475

36 Chan J, Spencer J. Adaptation to hand injury: an evolving experience. Am J Occup Ther 2004;58(02):128-139

37 Galanakos SP, Bot AG, Zoubos AB, Soucacos PN. Psychological and social consequences after reconstruction of upper extremity trauma: methods of detection and management. J Reconstr Microsurg 2014;30(03):193-206

38 Gustafsson M, Hagberg L, Holmefur M. Ten years follow-up of health and disability in people with acute traumatic hand injury: pain and cold sensitivity are long-standing problems. J Hand Surg Eur Vol 2011;36(07):590-598

39 Egeler SA, de Jong T, Luijsterburg AJM, Mureau MAM. Long-term patient-reported outcomes following free flap lower extremity reconstruction for traumatic injuries. Plast Reconstr Surg 2018; 141(03):773-783

40 Aerny-Perreten N, Domínguez-Berjón MF, Esteban-Vasallo MD, García-Riolobos C. Participation and factors associated with late or non-response to an online survey in primary care. J Eval Clin Pract 2015;21(04):688-693

41 Hutchings A, Neuburger J, Grosse Frie K, Black N, van der Meulen J. Factors associated with non-response in routine use of patient reported outcome measures after elective surgery in England. Health Qual Life Outcomes 2012;10:34

42 Kim J, Lonner JH, Nelson CL, Lotke PA. Response bias: effect on outcomes evaluation by mail surveys after total knee arthroplasty. J Bone Joint Surg Am 2004;86(01):15-21

43 Bot AGJ, Anderson JA, Neuhaus V, Ring D. Factors associated with survey response in hand surgery research. Clin Orthop Relat Res 2013;471(10):3237-3242 